\title{
NOVOS CONTORNOS DO CRESCIMENTO URBANO BRASILEIRO? \\ O CONCEITO DE URBAN SPRAWL E OS DESAFIOS PARA O PLANEJAMENTO REGIONAL E AMBIENTAL ${ }^{1}$
}

\author{
RICARDO OJIMA ${ }^{2}$ \\ Núcleo de Estudos Populacionais (NEPO) \\ Universidade Estadual de Campinas
}

\section{Introdução}

A primeira década do século XXI ficará marcada na história como o momento no qual o mundo passou pela transição urbana, pois segundo as estimativas da ONU 2007-2008 será o momento em que mais de 50\% da população do mundo passará a viver em áreas consideradas urbanas (UNFPA, 2007). Embora essa marca já tenha sido superada pelo Brasil em meados da década de 1960, novos desafios emergem para a compreensão dos processos sociais circunscritos na peculiaridade da vida urbana. A dicotomia rural-urbana, a peri-urbanização, as formas de assentamento ilegal, a periferização, enfim, um conjunto importante de marcos teóricos está em debate, sobretudo pela emergência de mudanças ambientais cada vez mais evidentes para a vida da população.

A expansão urbana assume recentemente novos contornos derivados de mudanças importantes na esfera da vida cotidiana e coloca novos desafios para o planejamento urbano e regional. Entre tais evidências estão os fluxos de movimentos populacionais diários dentro das principais

\footnotetext{
1 Este estudo foi desenvolvido no âmbito dos projetos: "Dinâmica intrametropolitana e vulnerabilidade sócio-demográfica nas metrópoles do interior paulista" (CNPq e FAPESP) e "Desafios para a urbanização sustentável no espaço intra-metropolitano de Campinas e Santos: mobilidade populacional, vulnerabilidade socioambiental e as evidências (locais, regionais e globais) das mudanças ambientais" (FAPESP), desenvolvidos no Núcleo de Estudos de População (NEPO/ Unicamp).

${ }^{2}$ Doutor em Demografia, pesquisador colaborador do Núcleo de Estudos de População (NEPO) e do Departamento de Demografia (DD/IFCH), ambos da Universidade Estadual de Campinas (Unicamp); bolsista de pós-doutorado pela Fundação de Amparo à Pesquisa do Estado de São Paulo (FAPESP).
} 
aglomerações urbanas brasileiras. Essa ampliação dos espaços de vida da população demanda uma nova abordagem para o entendimento dos processos intra-urbanos.

\begin{abstract}
Antes o que tínhamos era a expansão de uma malha contínua a se espraiar e estender a partir do que conhecíamos enquanto cidade sobre o espaço "natural", hoje esta disseminação dá-se de forma difusa e segmentada sem que haja necessariamente uma continuidade e contigüidade física entre os aglomerados e emerge em diversos pontos e manchas (Limonad, 2005).
\end{abstract}

Assim, devemos considerar pelo menos dois fatores como essenciais para a análise do processo de crescimento urbano recente. Um deles é o fator populacional e outro, talvez menos evidente, seja o padrão de expansão física das ocupações urbanas. O fator populacional representa um desafio em si mesmo quando exerce um importante peso na expansão da infra-estrutura urbana. Porém, em um momento em que mudam significativamente os fluxos migratórios para estas áreas urbanas, o padrão de ocupação pode e deve ser entendido como um fator essencial para que esse crescimento possa se dar com maior ou menor custo social.

Segundo Angel (2006), há que se distinguir estes dois processos, pois é natural que o crescimento da população urbana leve a um crescimento das áreas urbanas para comportar esse contingente populacional dentro das cidades. Mas o que se desenha enquanto um desafio particular ao crescimento das áreas urbanas no século XXI no Brasil não é apenas a pressão dos números, mas como as formas urbanas se moldam sob as tensões do crescimento populacional. É preciso, portanto, dar-se conta de "uma sociedade virtualmente urbana" (MONTE-MOR, 2006:11) em que as relações de consumo se dispersam por extensões indefinidas do espaço e consolidam novos padrões de vida em escalas de produção distintas.

Duas aglomerações urbanas podem apresentar taxas de crescimento populacional semelhantes no mesmo período, mas uma pode configurar uma forma urbana compacta, verticalizada e monocêntrica; enquanto outra pode conformar o seu espaço urbano de modo disperso, horizontalizado e policêntrico. Mas como e porque estes padrões podem ser considerados desafios para o planejamento regional, sobretudo ao que se refere ao futuro sustentável das cidades?

Este artigo tem, portanto, como objetivo central realizar um sobrevôo teórico acerca de questões relacionadas ao crescimento urbano a partir de uma abordagem que incorpora a dimensão dialética que circunscreve a produção social do espaço urbano. Para isso, buscou-se resgatar o debate 
em torno do conceito de urban sprawl. Embora esta seja uma abordagem que, à primeira vista, parece tratar essencialmente do processo de urbanização norte-americano, procura-se avançar na sua delimitação conceitual e avaliar em que medida ele pode representar um avanço metodológico para a compreensão dos fenômenos urbanos e para o planejamento urbano, regional e ambiental também no caso brasileiro.

\section{Uma revisão sobre o conceito/termo Urban sprawl}

O termo urban sprawl (doravante sprawl) surge em meados da década de 1960 como uma designação pejorativa para expressar a expansão descontrolada das aglomerações urbanas norte-americanas, sobretudo pela disseminação do padrão suburbano de urbanização (KIEFER, 2003). E se refere, basicamente, a um padrão de ocupação urbano de baixa densidade onde o padrão arquitetônico está associado a domicílios de maior área construída designado a habitações unifamiliares.

Embora a conceituação do termo ainda seja controversa na literatura internacional, é grande o número de pesquisas que apontam para o avanço deste fenômeno. $\mathrm{O}$ caso de Los Angeles é um dos mais associados a este processo, pois entre 1970 e 1990, a população da cidade cresceu em torno de $45 \%$, enquanto que, no mesmo período, a área urbana ocupada por esta população cresceu em 300\% (MEADOWS, 1999). Ou seja, houve uma redução significativa na densidade urbana dessa região, sobretudo, pelo avanço da ocupação de áreas periféricas em detrimento à importância desempenhada pelo centro urbano consolidado.

Em linhas gerais, o consenso sobre o debate é o descompasso entre o crescimento populacional e a expansão física do espaço urbano, isto é, a condução para baixas densidades urbanas. Neste sentido, podemos encontrar diversos estudos que mostram a distorção urbana de Los Angeles ocorrendo em diversas regiões dos Estados Unidos e em outras regiões do mundo. Mesmo nas cidades européias, tradicionalmente associadas ao seu desenho urbano compacto (RICHARDSON e CHANG-HEE, 2004), há sinais de que uma forma de urban sprawl se encontra cada vez mais presente.

De modo geral, essas abordagens se apóiam em estudos de caso, evidenciando o processo histórico de ocupação urbana e como o desenho urbano mudou ao longo do tempo nestas regiões. Entretanto, do ponto de vista histórico, o crescimento das áreas urbanas segundo um padrão de expansão periférico não é novidade; de certa forma, foi sempre assim que 
se deu o processo de ocupação humana no território. O que parece ser novo são as formas espaciais que essa ocupação urbana passa a assumir ao longo do século XX. Segundo Richardson e Chang-hee (2004:1), parece haver uma convergência nos padrões de assentamento urbanos encontrados nos Estados Unidos e na Europa Ocidental.

Essa transição pode ser percebida pelos estilos de vida que se disseminam através dos principais centros urbanos que, impulsionados por um processo de mundialização dos padrões de consumo, tendem a modelos cada vez mais homogêneos em diferentes regiões do mundo. A relativa dependência pelo transporte de uso individual passa a ser uma característica marcante e, de certa forma, joga um importante papel na compressão do espaço e do tempo nas cidades pós-modernas.

Mas quando o meio ambiente e a natureza passam a ser valores socialmente relevantes para aqueles que possuem condições econômicas para a opção da localização residencial, emerge uma contradição implícita nos estilos de vida urbanos. Ou seja, se por um lado queremos e passamos a viver predominantemente nas cidades, por outro, queremos voltar a viver perto da natureza. Segundo Dagger (2003), a dispersão urbana é resultado das escolhas individuais e se a demanda é por viver em áreas relativamente próximas aos centros urbanos com proximidade a valores relacionados ao meio ambiente, é natural que a urbanização seja mais dispersa, mesmo que coletivamente esse padrão traga efeitos negativos.

Neste aspecto, mais do que um fenômeno empiricamente observável na cidade contemporânea, a dispersão urbana é um processo social relacionado ao estilo de vida enaltecido pela modernidade. Enfim, trata-se dos valores da sociedade moderna e de suas expectativas em relação ao padrão de consumo. É exatamente nessa contradição que residem os principais problemas em torno do sprawl, pois, a expansão desse padrão de consumo ao longo do globo se dá com maior intensidade nos dias atuais e os desafios para a sustentabilidade urbana residem exatamente na manutenção desse padrão.

Os Estados Unidos da América simbolizam este padrão de ocupação que tem passado por inúmeras críticas tanto por parte dos organismos de gestão como movimentos da sociedade civil na busca de alternativas a este modelo de desenvolvimento urbano (RICHARDSON e CHANG-HEE, 2004). Mas, apesar de utilizarem instrumentos analíticos sofisticados como imagens de satélite, sistemas de informação geográficos e outros, os estudos que procuram caracterizá-lo não têm elaborado um tratamento conceitual refinado. De forma geral, a literatura sobre o sprawl confunde causas com conseqüências e, por isso, tende a ser uma denominação para 
uma diversidade de condições diferentes, o que abre margem para várias interpretações distintas e muitas vezes contraditórias. Assim, na maioria dos casos, o termo sprawl é atribuído à expansão territorial descontrolada das cidades levando a uma diminuição das densidades populacionais urbanas (GALSTER et al., 2000).

Trata-se da difusão da edge city (cidades de contorno), com a formação de verdadeiros simulacros de cidades em áreas relativamente distantes e até certo ponto desconectadas do contexto dos centros urbanos consolidados. Segundo Garreau (1988), primeiro a usar o termo edge city, essas ocupações são, sobretudo, os enclaves de alta renda onde se encontram as ocupações urbanas residenciais unifamiliares com alto padrão de consumo. Com maior evidência no período pós-Segunda Guerra, os Estados Unidos observaram o crescimento deste tipo de ocupação, simbolizando o American way of life, ou seja, a segregação espacial de camadas da população em busca de uma suposta qualidade de vida oposta aos valores dos antigos centros consolidados das cidades.

Tal padrão de ocupação traz consigo ainda a necessidade de novos locais de comércio e serviços que atendam aos novos padrões de consumo. Assim, como conseqüência, surgem os shopping centers para dar vazão às demandas de consumo da sociedade moderna de modo a satisfazer a lógica de deslocamento orientado para automóveis, demandando, cada vez mais, a utilização de vias de acesso "rápidas". Não se trata apenas de uma nova forma de habitação com inspiração em antigas formas de viver, trata-se de todo um conjunto de novas significações e representações sociais que permeiam não apenas aquela parcela da população de poder aquisitivo mais elevado, mas também um novo estilo de vida que é disseminado para todas as sociedades e camadas sociais; ou seja, o status não é mais apenas uma condição locacional, mas também uma condição estrutural da forma de habitação e modo de vida que ela inspira.

Mas o uso do termo sprawl não deve ser reduzido apenas às formas de ocupação de estilo "suburbano" norte-americano e seu correspondente no caso brasileiro: os condomínios fechados. Isso seria um reducionismo perigoso, pois em termos metodológicos a abordagem utilizada pelos estudos que procuram avaliar o sprawl contém um conjunto de análises que escapam à tradição brasileira. Ou seja, a escala sobre a qual se dá este fenômeno assume dimensões que vão além da análise da cidade ou de sua formação histórica. A escala de análise do processo de dispersão urbana (urban sprawl) é uma escala regional onde a cidade extravasa os limites da continuidade física da mancha urbanizada. 
Assim, uma característica discutida pela bibliografia sobre o sprawl é o desenvolvimento urbano não-conurbado (leapfrog development). Este modelo se remete basicamente à questão da forma e alocação fragmentada da mancha urbanizada para além do conceito de cidade, pois esta se configura cada vez mais sob os contornos de uma região, uma cidaderegião. Trata-se do aumento das distâncias entre os núcleos de desenvolvimento urbano de uma mesma dinâmica regional. Neste contexto, uma das questões envolvidas na expansão urbana e no conceito de urban sprawl é a crescente mobilidade espacial da população e uma relativa autonomia destes deslocamentos urbanos diários. Assim, a modernização que se ampliou após a Segunda Guerra Mundial em termos da disseminação do transporte individual, ampliou consideravelmente a extensão dos espaços de convivência diários que uma pessoa podia atingir ${ }^{3}$.

Segundo Richardson e Chang-hee (2004:7), essa dispersão urbana não é um fenômeno restrito aos Estados Unidos. É um processo que se repete também na Europa Ocidental, indicando que existem mais convergências do que divergências neste processo de urbanização. $O$ caso francês, identificado por Pumain (2004), salienta que se trata de um processo recente e que as evidências apontam para importantes mudanças nos processos que se refletem nos contextos urbanos. Na França, entre 1968 e 1999, a área urbanizada cresceu 5 vezes enquanto a população dessas áreas cresceu apenas 50\%.

Embora existam ainda problemas na identificação e comparação entre os processos ao longo do território europeu, há certo consenso de que, em relação aos países de tradição anglo-saxônica, a dispersão urbana tem um histórico mais recente em países como a França; e mais recente ainda em países como Espanha, Itália e outros países da Europa mediterrânea (PUMAIN, 2004). O caso espanhol é avaliado por Munoz (2003) e Roca et al. (2004) a partir do caso de Barcelona e identifica o aumento significativo de assentamentos urbanos em áreas cada vez mais externas ao centro consolidado. Segundo Munoz (2003), há a substituição do modelo denso e compacto das cidades mediterrâneas para um modelo muito semelhante àquele caracterizado como o arquétipo dos subúrbios norte-americanos.

No caso latino-americano, a expansão das áreas urbanas se deu de forma diferenciada tanto em termos cronológicos como em relação aos processos sociais subjacentes. Por um lado, observou-se uma expansão da

${ }^{3}$ A abordagem utilizada por Jean Gottman já considerava esta característica como parte importante da expansão urbana através do conceito de megalópole, na década de 1960. 
área urbana pela "expulsão" da população mais pobre e vulnerável para as áreas mais afastadas dos centros consolidados, marcando um paradigma que se cristalizou em torno da dicotomia centro-periferia. Este processo foi fortemente marcado pelo processo de verticalização dos centros urbanos e a conseqüente valorização do solo nestas áreas. Recentemente, novos processos passaram a se associar a este padrão de periferização da pobreza com a inclusão de um padrão muito mais semelhante ao norte-americano, valorizando assim as regiões mais distantes dos centros e normalmente associados a amenidades ambientais.

No caso brasileiro, embora ainda não seja consenso, o processo de urbanização apresenta sinais de mudanças importantes. O número de condomínios e loteamentos fechados já é expressivo e, devido às suas características construtivas, a analogia com o padrão norte-americano é visível. Segundo Caldeira (2000), o surgimento de condomínios e loteamentos faz parte de um novo padrão de segregação espacial e desigualdade social na cidade, substituindo aos poucos $\mathrm{o}$ padrão dicotômico centro-periferia (rico-pobre).

Mas apesar de podermos dizer que se trata de uma tendência que abrange uma pequena parcela da população, aquela de alto poder aquisitivo, esse padrão possui reflexos importantes para toda a sociedade, especialmente no que se refere à reestruturação do espaço urbano. Por um lado, altera as tensões sociais dentro do tecido urbano, tornando os espaços intra-urbanos mais fragmentados e segregados ${ }^{4}$. Por outro lado e, talvez, o mais importante, dinamiza e orienta os processos de estruturação urbana, pois passa a ser o parâmetro para o padrão de consumo do espaço urbano.

Assim, passa a representar um modelo de consumo difundido entre diversas camadas sociais. O mercado imobiliário já passa a direcionar investimentos para consumidores diversificados através de empreendimentos que vão desde $\mathrm{R} \$ 30$ mil até $\mathrm{R} \$ 3$ milhões só na Região Metropolitana de São Paulo (EMBRAESP, 2006). Assim, as regiões periféricas, distantes dos centros consolidados das aglomerações urbanas e que antes eram reservadas aos conjuntos habitacionais populares, passam a ser o sonho de consumo de uma variada parcela da população, traduzindo as aspirações de uma determinada qualidade de vida.

${ }^{4}$ Fragmentação se refere à dimensão espacial do tecido urbano, quando a mancha urbanizada se configura em espaços desconectados e não conurbados. A segregação deve ser entendida aqui não apenas em termos espaciais, mas principalmente pelo conflito inerente ao convívio urbano. 
O condomínio fechado pode ser entendido, portanto, como expressão máxima da globalização dos padrões de consumo, mas não resume as aplicações do conceito de urban sprawl no processo de expansão urbana brasileiro. Cabe destacar que a principal contribuição dessa abordagem teórico-metodológica que vem dos estudos norte-americanos sobre o urban sprawl é a análise da dimensão espacial enquanto uma categoria analítica cara ao entendimento da reestruturação urbana a partir de mudanças na esfera das decisões individuais e coletivas. Assim, não se trata de importar conceitos aplicáveis a realidades sociais distintas, mas de adaptar a apreensão dos fatores sociodemográficos dentro de uma abordagem empírica que resgate componentes teóricos e metodológicos não incorporados pela tradição dos estudos urbanos no Brasil.

\section{Conseqüências inesperadas e os desafios para a sustentabilidade}

Entre as principais questões relacionadas ao estudo do urban sprawl está a sustentabilidade ambiental. Os estudos que envolvem as preocupações com essa expansão descontrolada do uso do solo relacionam esse processo a um conjunto importante de impactos sociais, econômicos e ambientais. Em termos dos estudos brasileiros, por estarem as periferias fortemente vinculadas aos espaços da pobreza, a análise dos impactos ambientais do processo de urbanização periférico sempre esteve focada nas relações entre pobreza e degradação ambiental. Entretanto, do ponto de vista dos estudos que partem da perspectiva do urban sprawl as características espaciais da expansão urbana possuem em si mesmas uma dimensão relevante.

Entre os principais aspectos relacionados ao debate está o uso intensivo de transporte automotivo, sobretudo o de uso individual. Embora essa característica possa ser atribuída tanto como conseqüência como causa, em resumo, quanto maiores as distâncias necessárias a serem percorridas entre as distintas esferas da vida cotidiana como trabalho, residência, estudo, compras, etc, maior será a demanda pelo uso dos meios de transportes.

O crescente uso de transporte automotivo é apontado como um fator central, pois traz consigo o aumento das emissões de gases de efeito estufa (GEE). O estudo conduzido por Ewing, Pendall e Chen (2002), relata a forte correlação entre o índice de dispersão urbana elaborado por sua 
pesquisa e os níveis extremos de concentração de ozônio troposférico ${ }^{5}$. Segundo eles, entre as diversas variáveis testadas para cada área metropolitana norte-americana considerada pela pesquisa, o grau de dispersão urbana foi o que melhor indicou os níveis de concentração de ozônio troposférico.

Um relatório publicado pelo Western Resources Advocates (2003) discute os impactos decorrentes do padrão de desenvolvimento suburbano como um dos principais responsáveis pelo aumento do consumo de água. Neste caso, o padrão de consumo associado aos parcelamentos de lotes residenciais cada vez maiores tende a consumir mais água, sobretudo pelo desperdício do uso nas áreas abertas nessas residências. Assim, não se trata exatamente de uma relação direta com o padrão de dispersão urbana em si, mas a relação encontrada no modelo norte-americano desses loteamentos suburbanos e o tipo de residência neles alocado.

Além disso, grande parte do desperdício de água está relacionado ao sistema de abastecimento, principalmente nas perdas ao longo do sistema de distribuição, como rompimento de adutoras, vazamentos, etc. Em função das maiores extensões da rede de abastecimento proporcionadas pelo crescimento das áreas a serem atendidas, as chances de que essas perdas ocorram aumentam proporcionalmente, sobretudo nos países em desenvolvimento.

Mas, em termos dos recursos naturais, talvez a expressão mais evidente seja a redução das áreas verdes. Ou seja, para que essa expansão da área urbanizada sob um padrão de baixas densidades seja viável, o que ocorre, na maioria dos casos, é a transformação das áreas peri-urbanas onde antes existiam atividades de interesse social como produção agrícola ou cinturões verdes. De certa forma, morar perto do campo com as vantagens de toda infra-estrutura dos centros urbanos é a tônica desse modelo de urbanização.

Em diversas partes do mundo as pessoas estão procurando escapar do tráfego intenso, do crime e ausência de espaços verdes e recriando "cidades" em áreas distantes dos centros consolidados. Mas a ironia desse processo é exatamente a reprodução em seus novos espaços residenciais

${ }^{5}$ Embora o ozônio seja importante para a proteção dos raios ultravioleta que incidem sobre a terra, quando este gás se concentra nas camadas mais baixas da atmosfera (troposfera) se torna um perigoso poluente, causando problemas respiratórios, danificando tecidos e plantas. Ele é produzido por reações fotoquímicas associadas à emissão de GEE e os principais gases envolvidos são o monóxido de carbono, metano e o óxido nitroso. 
dos mesmos problemas pelos quais esses moradores tentaram fugir. Estes subúrbios que serviam como refúgio aos problemas antes restritos aos antigos centros passam a reproduzir problemas em uma escala talvez mais crítica pela ausência e/ou a dificuldade de se proporcionar a infra-estrutura que só se torna viável em áreas residenciais mais densas como, por exemplo, um sistema de transporte coletivo, segurança pública, educação e serviços de saúde.

A ocupação residencial de áreas antes ocupadas por outras atividades econômicas também traz consigo conseqüências importantes à qualidade de vida da população e que nem sempre são perceptíveis imediatamente. A construção de conjuntos habitacionais em áreas antes dedicadas a atividades industriais ou de alguns tipos de atividades agrícolas pode levar a uma maior exposição da população a solos e água contaminados, levando a problemas de saúde crônicos e muitas vezes sem que a causa seja identificada imediatamente. Em termos da saúde da população, as pesquisas apontam para relações muito mais graves em casos onde a dispersão urbana é mais acentuada. Um dos sinais mais evidentes e relacionado ao aumento da necessidade de transportes automotivo é o maior índice de acidentes de transporte.

Ewing, Pendall e Chen (2002), apontam para essa relação entre os acidentes de transporte fatais e o grau de dispersão urbana. Segundo eles, ainda que áreas urbanas mais compactas possuam maiores taxas de uso de veículos, lugares com maior dispersão tendem a ter mais acidentes fatais. Esta relação foi testada pela pesquisa e controlada por variáveis como renda per capita e se mostrou estatisticamente significativa para os diversos indicadores de dispersão urbana avaliados pela pesquisa.

Efeitos na saúde da população também assumem papel importante quando se observa a crescente incidência de doenças tradicionalmente associadas a áreas rurais ocorrendo em populações urbanas. Doenças como raiva e a febre maculosa, embora não sejam endêmicas, aparecem eventualmente como surtos em algumas regiões densamente urbanizadas do Brasil.

Outra relação interessante foi identificada pela pesquisa desenvolvida por McCann e Ewing (2003). Segundo esta pesquisa, as pessoas que vivem em áreas de urbanização dispersa tendem a ter um maior índice de massa corporal, sendo que as pessoas que vivem em áreas mais compactas pesam em média $2,7 \mathrm{~kg}$ menos do que aquelas que vivem em áreas mais dispersas, além de apresentarem também maiores índices de hipertensão e pressão arterial. O que explicaria essa relação é o fato de que pessoas que 
vivem nessas regiões tendem a andar e caminhar menos, explicando a tendência a serem mais obesas.

De fato, é uma relação importante, pois, mesmo entre as pessoas que praticam atividades físicas regularmente, aquelas que vivem em áreas mais compactas tendem a ter menos índice de massa corporal. O que, de certa forma, indica que parte da atividade física que pode ser realizada durante as próprias atividades do cotidiano tem peso importante na vida das pessoas.

\section{Considerações finais: uma agenda para pesquisa e os desafios para o planejamento regional e ambiental}

Como vimos, há um conjunto importante de referências que podem ser feitas em termos das distintas formas de distribuição espacial da população urbana. Impactos que vão desde a saúde humana até a poluição atmosférica podem sofrer influências da forma urbana. Com a incorporação dos Sistemas de Informação Geográfica (SIG), tornou-se possível compatibilizar imagens de satélite, informações geográficas e socioeconômicas com uma precisão até então nunca utilizada e, dessa forma, passou a ser possível qualificar a forma urbana, além de apenas quantificá-la ou descrevê-la em estudos de caso isolados.

Dessa forma, os impactos avaliados pelos diversos estudos mostram que o urban sprawl pode ser entendido como um conceito que vai além da mera analogia do crescimento urbano no estilo dos subúrbios norteamericanos, pois os estudos conduzidos nas áreas metropolitanas norteamericanas não se restringem à análise dos arquétipos urbanos contidos por estas formas de assentamentos. Trata-se de uma abordagem que pode trazer uma importante contribuição para o entendimento das cidades que se conformam sob dinâmicas regionais, principalmente no caso brasileiro, onde as políticas locais são fortemente vinculadas à dinâmica dos municípios e não do contexto urbano no qual elas se inserem.

Ou seja, uma determinada aglomeração urbana pode ser distinta não apenas em termos do aumento da área urbanizada ou do crescimento populacional, mas também pelos desenhos e formas dos espaços intraurbanos. Isso quer dizer que, mesmo que a densidade urbana seja semelhante em duas regiões, configuram-se distintas formas de tecido urbano, mais ou menos desconectado, com maior ou menor diversidade das atividades ou heterogeneidade de funções. 
Em termos espaciais, a análise da cidade moderna sempre foi confundida com a análise da cidade industrial monocêntrica; neste modelo, a dicotomia centro-periferia se destaca como expressão mais freqüente e ratifica certa homogeneidade nos distintos espaços intra-urbanos. Entretanto, parece haver um novo cenário em que o espaço urbano assume uma estruturação cada vez mais extensiva, sobretudo pela ramificação das redes urbanas para além da integração dos fluxos econômicos, mais perceptível nos contextos metropolitanos, mas não limitado a eles. Portanto, surge como nova evidência a intensificação dos fluxos de mobilidade populacional e a mudança nos padrões de consumo. Assim, uma aglomeração pode assumir distintas formas de se dispersar no espaço e, por suposto, essas diferentes formas podem assumir impactos sociais e ambientais diferenciados.

Com as estimativas da ONU de que o ano de 2007-08 representa o ponto de inflexão na distribuição da população mundial para uma condição predominantemente urbana, cada vez mais será importante superar os limites entre as perspectivas sociológicas e formais no que se refere ao estudo das cidades-região contemporâneas. Além disso, as perspectivas de mudanças ambientais globais apontam para importantes demandas que se referem exatamente ao modo de vida urbano. Não apenas em termos da incorporação de novos padrões de consumo menos poluentes, mas também aquelas relacionadas ao impacto direto que a maior incidência de eventos climáticos extremos ou a elevação do nível dos oceanos pode causar sobre a vida cotidiana nos aglomerados urbanos suscetíveis a estes processos. Enfim, são desafios que se somam àqueles que ora enfrentamos e que, frente ao processo de globalização, serão ampliados e intensificados.

\section{NOVOS CONTORNOS DO CRESCIMENTO URBANO BRASILEIRO? O CONCEITO DE URBAN SPRAWL E OS DESAFIOS PARA O PLANEJAMENTO REGIONAL E AMBIENTAL}

Resumo: A transição para um mundo predominantemente urbano, segundo as estimativas da ONU, nos coloca frente a novos desafios para entender os processos sociais e espaciais que se configuram nas aglomerações urbanas brasileiras. Portanto, a incorporação de abordagens que incluam a dinâmica regional e espacial é fundamental para ampliar o escopo dos estudos urbanos. A partir deste trabalho, resgatamos a abordagem do urban sprawl da literatura norte-americana no objetivo de entender quais são as suas contribuições para o caso brasileiro, colocando um novo conjunto de questões onde a preocupação com as mudanças ambientais se torna cada vez mais presente na vida cotidiana. 
Palavras-Chave: Urbanização; Dispersão Urbana; Meio Ambiente ARE THERE NEW OUTLINES OF THE BRAZILIAN URBAN GROWTH? THE URBAN SPRAWL CONCEPT AND THE CHALLENGES FOR THE REGIONAL AND ENVIRONMENTAL PLANNING

Abstract: The transition for a predominantly urban world, accordingly UN estimative, put us into new challenges to understand the social and spatial processes that are being configured in Brazilian urban agglomerations. Therefore, incorporating approaches that include regional and spatial dynamics is fundamental to extend the urban studies field. Through this paper we review the approach of urban sprawl from the US literature to understand which are its main contributions to the Brazilian case, presenting a new group of questions where the concern with environmental change become much more present in everyday life.

Key words: Urbanization; Urban Sprawl; Environment

\section{BIBLIOGRAFIA}

ANGEL, S. (2006) Measuring Global Sprawl: The Spatial Structure of the Planet's Urban Landscape, mimeo.

CALDEIRA, T. P. R. (2000) Cidade de muros: crime, segregação e cidadania em São Paulo, São Paulo: Editora34/Edusp.

DAGGER, R. (2003) Stopping sprawl for the good of all: the case for civic environmentalism. Journal of Social Philosophy 34, 1, 28-43.

EMPRESA BRASILEIRA DE ESTUDOS DO PATRIMÔNIO (EMBRAESP). Estatísticas da Região Metropolitana de São Paulo: Empreendimentos Residenciais. <www.embraesp.com.br>, acesso em: março de 2006.

EWING, R. PENDALL, R. e CHEN, D. (2002) Measuring Sprawl and its Impacts. Smart Growth America, October 2002. Disponível em: http://www.smartgrowthamerica.org.

KIEFER, M.J. (2003) Suburbia and its Discontents. Harvard Design Magazine, n.19, p.1-5.

LIMONAD, E. (2005) Entre a urbanização e a sub-urbanização do território. XI Encontro Nacional da Associação Nacional de Pós-graduação e Pesquisa em Planejamento Urbano e Regional - ANPUR, Anais... Salvador, 23 a 27 de maio de 2005. Salvador: ANPUR. 
MACCANN, B.A. e EWING, R. (2003) Measuring the health effects of sprawl: a national analysis of physical activity, obesity and chronic disease. Smart Growth America, Washington: Surface Transportation Policy Project.

MONTE MOR, R. L. (2006) O que é o urbano no mundo contemporâneo. In: Texto para Discussão. Belo Horizonte: UFMG/Cedeplar, 14p.

MUNOZ, F. (2003) Lock living: urban sprawl in Mediterranean cities. Cities, 20, 6, p.381-385.

GALSTER, G., HANSON, R., WOLMAN, H., COLEMAN, S. e FREIHAGE, J. (2001) Wrestling sprawl to the ground: defining and measuring an elusive concept, Housing Policy Debate, v.12, issue 4, Fannie Mae Foundation, p. 681-717.

GARREAU, J. (1988) Edge City: Life on the new frontier, Nova York: Doubleday.

MEADOWS, D.H. (1999) So what can we do - really do - about sprawl. In: Sprawl Articles, Sierra Club, http://www.sierraclub.org/sprawl/articles/ meadows3.asp.

PUMAIN, D. (2004) Urban sprawl: is there a French case? In: RICHARDSON, H.W. e CHANG-HEE C.B. (eds.) Urban sprawl in Western Europe and United States. Bodmin: Ashgate, pp. 137-157.

RICHARDSON, H. W. e CHANG-HEE, C. B. (org.) (2004) Urban Sprawl in Western Europe and the United States. Bodmin: Ashgate.

ROCA, J., BURNS, M.C. e CARRERAS, J.M. (2004) Monitoring urban sprawl around Barcelona's Metropolitan Area with the aid of satellite imagery. XXth ISPRS Congress, 12-23 July, Istanbul.

UNFPA United Nations Population Fund (2007) State of World Population 2007: Unleashing the potential of Urban Growth. UNFPA: New York.

WESTERN RESOURCES ADVOCATES (2003) Smart Water: a comparative study of urban water use across the southwest. Disponível em: http://www.westernresourcesadvocates.org. Consultado em: novembro de 2006. 